\title{
Inhibitory effect of Zn2 + on the chain-initiation process of cumene oxidation
}

\author{
Zhicheng Chen ${ }^{1}$, Yuhang $\mathrm{Li}^{2}$, Yonghai $\mathrm{Cao}^{3}$, Qiao Zhang ${ }^{1}$, Hao $\mathrm{Yu}^{3}$, and Feng Peng ${ }^{1}$ \\ ${ }^{1}$ Guangzhou University \\ ${ }^{2}$ Sun Yat-Sen University \\ ${ }^{3}$ South China University of Technology
}

May 4, 2021

\begin{abstract}
Carbon nanotubes (CNTs) have excellent catalytic activity in liquid phase reaction, especially in aerobic oxidation of cumene. In previous work, the conversion of cumene was $41.8 \%$ and the selectivity of cumene hydroperoxide was $71.5 \%$, which was catalyzed by CNTs. But a small amount of impurity $\mathrm{Zn} 2+$ totally blocked up the aerobic oxidation of cumene that catalyzed by CNTs, which is an unexpected discovery. By analyzing the catalytic mechanism of CNTs, the inhibition effect of Zn2 + is locked on the abstraction of $\mathrm{H}$ atom from cumene. The inhibition of $\mathrm{Zn} 2+$ is confirmed in two effects by density functional theory (DFT) calculations. Firstly, due to the strongly coordination of active oxygen species (ROS) by Zn2+, the energy barrier of initial reaction increases to $1.90 \mathrm{eV}$, which is nearly 4 times higher than that of the only ROS promoted-process. Secondly, the interaction of $\mathrm{Zn} 2+$ and RO. or ROO. to inhibits the chain propagation reaction of free radicals. This work precisely demonstrates that the inhibition effect of $\mathrm{Zn} 2+$ on initial reaction of cumene. The most significant thing is that the effect of metallic heteroatoms is not negligible in organic oxidation reaction.
\end{abstract}

\section{Inhibitory effect of $\mathrm{Zn}^{2+}$ on the chain-initiation process ofcumene oxidation}

Zhicheng Chen ${ }^{\mathrm{a}}$, Yuhang Li*c, Yonghai Cao ${ }^{\mathrm{b}}$, Qiao Zhang ${ }^{\mathrm{a}}$, Hao Yu ${ }^{\mathrm{b}}$ and Feng Peng*a

a School of Chemistry and Chemical Engineering, Guangzhou University, Guangzhou 510006, China.

b School of Chemistry and Chemical Engineering, South China University of Technology, Guangzhou 510640, China

c School of Chemistry, Sun Yat-sen University, Guangzhou 510275, China

* Corresponding author, E-mail: liyh@mail.sysu.edu.cn (Y. Li);

fpeng@gzhu.edu.cn (F. Peng)

Abstract: Carbon nanotubes (CNTs) have excellent catalytic activity in liquid phase reaction, especially in aerobic oxidation of cumene. In previous work, the conversion of cumene was $41.8 \%$ and the selectivity of cumene hydroperoxide was $71.5 \%$, which was catalyzed by CNTs. But a small amount of impurity $\mathrm{Zn}^{2+}$ totally blocked up the aerobic oxidation of cumene that catalyzed by CNTs, which is an unexpected discovery. By analyzing the catalytic mechanism of CNTs, the inhibition effect of $\mathrm{Zn}^{2+}$ is locked on the abstraction of $\mathrm{H}$ atom from cumene. The inhibition of $\mathrm{Zn}^{2+}$ is confirmed in two effects by density functional theory (DFT) calculations. Firstly, due to the strongly coordination of active oxygen species (ROS) by $\mathrm{Zn}^{2+}$, the energy barrier of initial reaction increases to $1.90 \mathrm{eV}$, which is nearly 4 times higher than that of the only ROS promoted-process. Secondly, the interaction of $\mathrm{Zn}^{2+}$ and $\mathrm{RO} \cdot$ or $\mathrm{ROO} \cdot$ to inhibits the chain propagation reaction of free radicals. This work precisely demonstrates that the inhibition effect of $\mathrm{Zn}^{2+}$ on initial reaction 
of cumene. The most significant thing is that the effect of metallic heteroatoms is not negligible in organic oxidation reaction.

Keywords: carbon catalysis; cumene oxidation; inhibition effect; DFT calculations

\section{Introduction}

Liquid-phase oxidation of hydrocarbons with molecular oxygen to high value-added products such as ketone, carboxylic acids, and alcohols is a very important industrial process. ${ }^{[1-3]}$ The liquid aerobic oxidation of cumene is a most crucial reaction, which can produce cumene hydroperoxide (CHP), acetophenone (AP) and 2-phenyl-2-propanol (PP). ${ }^{[4,5]}$ Those oxidation products are intermediate platform molecules to produce fine synthetic chemicals such as phenol, fragrances, and polyesters. For instance, over $95 \%$ of world production of phenol is produced by the conversion of CHP. ${ }^{[6,7]}$ To pursue high performance catalysts, a great deal of research about catalytic reaction have been done for decades. ${ }^{[8,9]}$

The nonmetallic, excellent catalytic performance and high stability of CNTs made them an excellent catalyst for selective oxidation. ${ }^{[10-12]}$ Based on our previous research, we found that CNTs possess excellent catalytic performance for the oxidation of cumene. ${ }^{[11,13-15]}$ The advantage of CNTs is that oxygen can be activated on the surface of CNTs to generate ROS, which has been reported. ${ }^{[16,17]}$ The catalytic performance of CNTs was further improved by doping nitrogen. ${ }^{[18]}$ Because doping nitrogen would cause the strong interaction between CHP and CNTs. ${ }^{[15]}$ The main oxidation product of cumene catalyzed by CNTs is CHP. ${ }^{[11,13,19]}$ In that way, cumene and CHP are able to react continuously on the surface of CNTs. Moreover, we recently found that the selectivity of the oxidation products would be changed by mixing different metal cocatalysts $\left(\mathrm{CuCl}_{2}, \mathrm{FeCl}_{3}, \mathrm{MnCl}_{2}\right.$ and so on) into the system catalyzed by CNTs, especially, the trace amount of $\mathrm{CuCl}_{2}$ could significantly improve the reactivity and regulate product selectivity for cumene oxidation. ${ }^{[14]}$

Most recently, we added a small amount of $\mathrm{ZnCl}_{2}$ as a co-catalyst and observed a curious result that the oxidation product could hardly be detected at the end of the reaction. To our best knowledge, this is the first time that this inhibition phenomenon has been found. A reasonable guess is that the key steps about the production of CHP were blocked by $\mathrm{ZnCl}_{2}$, while the generation of $\mathrm{AP}$ and $\mathrm{BP}$ is related to the participation of CHP. Thus, inhibiting the production of CHP leads to no oxidation products at the end of the reaction. To find out how $\mathrm{ZnCl}_{2}$ works in the oxidation reaction of cumene, the interactions between $\mathrm{ZnCl}_{2}$ and key reactants should be considered by DFT. This work is of great significance to reveal the influence of impurity of metal ion on the oxidation of cumene, and to have a deeper understanding of carbon catalyzed radical oxidation reaction.

\section{Experimental}

\subsection{Cumene oxidation}

CNTs used in the oxidation reaction of cumene were obtained from Zhongshan CNM Plastic Co., Ltd., and the metal impurities in CNTs were tested by ICP-AAS. $\mathrm{ZnCl}_{2}, \mathrm{ZnBr}_{2}$ and $\mathrm{ZnAc}_{2}$ were used as additive, which were purchased from Aladdin.

The cumene oxidation reaction was carried out in a three-neck flask $(25 \mathrm{~mL})$, supplied with a magnetic stirrer, reflux condenser and the oil bath. Firstly, CNTs $(100 \mathrm{mg})$, additive $(10 \mathrm{mg})$, and cumene $(10 \mathrm{~mL})$ were added into the flask, sonicated for $5 \mathrm{~min}$, then heated to preconcerted temperature $(80)$ followed by the bubbling of $25 \mathrm{~mL}^{*} \mathrm{~min}^{-1}$ oxygen for $8 \mathrm{~h}$. When the reaction was over, the reaction mixture was cooled to room temperature and filtered to separate the liquid for detection. The concentration of CHP was determined according to the iodometric method. ${ }^{[20]}$ After the reduction of CHP to PP via triphenylphosphine reaction, the other liquid products were detected by gas chromatography (an Agilent GC-7890B) equipped with a DB-1701 capillary column (30 $\mathrm{m} \times 0.25 \mathrm{~mm} \times 0.25 \mu \mathrm{m})$ and a flame ionization detector.

\subsection{Computational methods}

As the CNTs using in reaction were $100 \mathrm{mg}$. Each radical reaction on the surface of CNTs is approximately on the two-dimensional plane, so DFT calculation is simulated on the graphene surface which belong to periodic 
system. DFT calculation were performed with the Dmol3 package. ${ }^{[21]}$ The configurations were optimized with GGA/PBE correlation exchange functional under DNP basis set. ${ }^{[22]}$ The Grimme' DFT-D was included as the long-range dispersion correction method. ${ }^{[23]}$ The k-point was set to $4 \times 4 \times 1$ for the self-consistent field (SCF) procedure. The conductor-like screening model (COSMO) with a permittivity of 2.4 was invoked to simulate the cumene solvent environment. ${ }^{[24]}$ The global orbital cutoff was $5.0 \AA$. Furthermore, the optimized structures were used for energy calculations and TS search with the same computational parameters. The LST/QST method was exploited to search the transition state of the reaction and the NEB method was adopted to confirm the transition state.

The relative system energy $(\Delta \mathrm{E})$ is calculated by equation (1):

$\Delta \mathrm{E}=\mathrm{E}_{\mathrm{Zn} 2+-\mathrm{RO}} \cdot-\mathrm{E}_{\mathrm{Zn} 2+}-\mathrm{E}_{\mathrm{RO}} \cdot+\mathrm{E}_{\mathrm{BSSE}}(1)$

where, $\mathrm{E}_{\mathrm{Zn} 2+-\mathrm{RO}}$. is the energy of the $\mathrm{Zn}^{2+}$ ion and $\mathrm{RO}$ - radical system, $\mathrm{E}_{\mathrm{Zn} 2+}$ is the energy of the $\mathrm{Zn}^{2+}$ ion, $\mathrm{E}_{\mathrm{RO}}$. is the energy of RO. and $\mathrm{E}_{\mathrm{BSSE}}$ is the energy of Basis Set Superposition Error. When the value of $\Delta \mathrm{E}$ is negative, it means that the interaction between two substances is favorable.

The energy barrier $\left(E_{a}\right)$ is calculated by equation (2):

$\mathrm{E}_{\mathrm{a}}=\mathrm{E}_{\mathrm{TS}}-\mathrm{E}_{\text {reactant }}(2)$

Where, $\mathrm{E}_{\mathrm{TS}}$ is the total energy of the transition state, $\mathrm{E}_{\text {reactant }}$ is the energy of the initiation state. The more positive the value of $\mathrm{E}_{\mathrm{a}}$, the harder this reaction is to do.

\section{Results and discussion}

\section{The inhibition phenomenon of $\mathrm{Zn}^{2+}$ oncumene oxidation}

The catalytic properties of cumene oxidation on different conditions are summed up in Table 1. Without any catalysts, cumene proceeds through an aerobic autoxidation. And the conversion was as low as $1.3 \%$ (entry 1). The conversion of cumene was increased to $41.8 \%$ after adding CNTs (entry 2). This illustrates that CNTs play a key role in the cumene oxidation. The studies found that CNTs had an active effect on $\mathrm{O}_{2} \cdot{ }^{[2,25,26]}$ However, after adding $10 \mathrm{mg} \mathrm{ZnCl}_{2}$ to the system (entry 3), the conversion of cumene was almost zero. No oxidative products were detected by iodometric method and gas chromatography, which means that the oxidation of cumene was totally stopped by $\mathrm{ZnCl}_{2}$. At the beginning, $\mathrm{Cl}^{-}$ion was suspected to be involved in inhibiting the oxidation reaction of cumene. While, $\mathrm{CuCl}_{2}, \mathrm{FeCl}_{3}$ and $\mathrm{CoCl}_{2}$ were added into cumene oxidation system catalyzed by CNTs, the conversion of cumene was not reduced, and even the activity was increased. ${ }^{[11,13-15]}$ Besides, the $\mathrm{ZnCl}_{2}$ was replaced with $\mathrm{ZnBr}_{2}$ on oxidation experimental and still none of any oxidation products could be detected at the end of reaction (entry 4). It is widely known that the radius of $\mathrm{Br}^{-}$ion is larger than that of $\mathrm{Cl}^{-}$ion, namely $\mathrm{ZnBr}_{2}$ would more likely dissociate $\mathrm{Zn}^{2+}$ into the system. Then $\mathrm{Zn}^{2+}$ is the most likely source of inhibition of cumene oxidation. In general, metals ions $\left(\mathrm{Cu}^{2+}, \mathrm{Co}^{2+}\right.$ etc.) can promote the active sites of aromatics oxidation. ${ }^{[27-29]}$ This particular inhibition of metal ions has received little attention. In practical industrial application, it is very important to analyze the effect of metal ion impurity on catalytic performance. In order to explore the inhibition effect of $\mathrm{Zn}^{2+}$, it is necessary to analyze the oxidation mechanism of cumene.

Table 1 Cumene oxidation catalyzed by CNTs with zinc compounds ${ }^{\mathrm{a}}$

\begin{tabular}{lllllll}
\hline Entry & Catalysts $(\mathrm{mg})$ & Catalysts $(\mathrm{mg})$ & Con. $(\%)$ & Sel. (\%) & Sel. (\%) & Sel. (\%) \\
\hline & $10 \mathrm{mg}$ & $100 \mathrm{mg}$ & Cumene & AP & PP & CHP \\
1 & None & None & 1.3 & 0 & 0 & 100 \\
2 & None & CNTs & 41.8 & 4.1 & 24.4 & 71.5 \\
3 & $\mathrm{ZnCl}_{2}$ & CNTs & 0.13 & - b $^{2}$ & - & - \\
4 & $\mathrm{ZnBr}_{2}$ & CNTs & 0 & - & - & - \\
\hline
\end{tabular}


a Reaction conditions: $10 \mathrm{~mL}$ cumene, $25 \mathrm{~mL} \mathrm{~min}^{-1} \mathrm{O}_{2}, 353 \mathrm{~K}, 8 \mathrm{~h}$.

b Oxidation products cannot be detected.

\section{The analysis of oxidation mechanism of cumene oxidation}

For decades, autoxidation chemistry has explained the oxidation of hydrocarbons in the absence of a catalyst. ${ }^{[30-33]}$ Now, it has been proposed to explain the oxidation mechanism of cumene with CNTs as catalysts, as shown in Figure 1. The reactions (1-5) that in network are the major reaction of cumene. ${ }^{[32,34]}$ The initial reaction (1) can be a unimolecular reaction or catalytic reaction. If it is the former, not only is this unimolecular dissociation very slow, but also the radical-pair (cumenyl radical (R.), H.) quickly recombines because of the effect of solvent cage. ${ }^{[35]}$ It has been reported that CNTs can activate $\mathrm{O}_{2}$, resulting in ROS catalyzing the reaction (1). Then the $\mathrm{R}$ - radical combines with $\mathrm{O}_{2}$ to produce the cumyl peroxy radicals (ROO.) (reaction 2). ROO is a reactive radical can abstract a $\mathrm{H}$ atom from cumene to produce $\mathrm{CHP}$ and $\mathrm{R}$. (reaction 3). Once CHP is produced, the CHP adsorbed on CNTs tends to decompose into cumenyl oxygen radical (RO.) (reaction 4), which can abstract a $\mathrm{H}$ atom from cumene to produce $\mathrm{R}$. The formed $\mathrm{R}$ - will go on enter the reaction (2). Combined with the above, there are three ways to the generation of crucial $\mathrm{R}$ - in reactions $(1,3,5)$ involving cumene. In these three reactions, the reactive species (ROO·, RO·, ROS) induce abstraction of $\mathrm{H}$ atom. It is possible that $\mathrm{Zn}^{2+}$ inhibits the reactivity of those species, thus completely inhibits the oxidation of cumene. To prove the point, the interaction of $\mathrm{Zn}^{2+}$ and those reactive substrates (ROO·, RO·, ROS) are calculated by DFT.

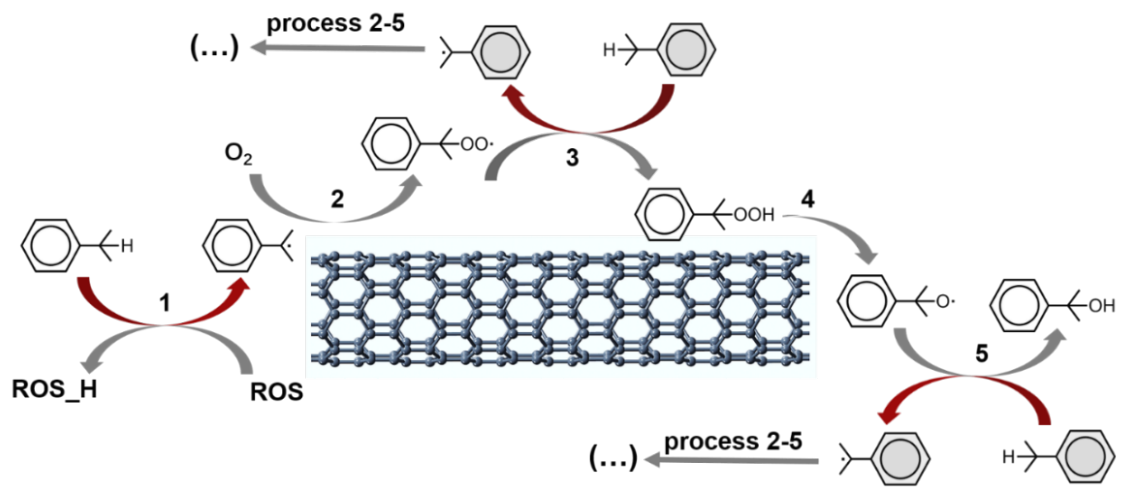

Figure 1 Reaction network of cumene catalyzed by CNTs.

$$
\begin{aligned}
& \mathrm{RH}-\mathrm{H} \cdot+\mathrm{R} \cdot(1) \\
& \mathrm{R} \cdot+\mathrm{O}_{2}-\mathrm{ROO}^{*}(2) \\
& \mathrm{ROO}^{*}+\mathrm{RH}-\mathrm{CHP}+\mathrm{R}^{*}(3) \\
& \mathrm{CHP}-\mathrm{RO}^{*}+{ }^{*} \mathrm{OH}(4) \\
& \mathrm{RO} *+\mathrm{RH}-\mathrm{ROH}+\mathrm{R}^{*}(5)
\end{aligned}
$$

\section{Theoretical calculation of inhibition effect of $\mathrm{Zn}^{2+}$ on cumene oxidation}

Firstly, a hypothesis is proposed that the life of free radicals is long enough to interact with $\mathrm{Zn}^{2+}$. This is conducive to calculating the interaction between $\mathrm{Zn}^{2+}$ and active radicals. Finally, combined with the actual situation, the revised results are discussed. So, whilst a $\mathrm{Zn}^{2+}$ is in cumene solvent, a $\mathrm{Zn}^{2+}$ is able to interacts with $\mathrm{ROO}^{*}$ and $\mathrm{RO}^{*}$. Considering the multiple coordination ability of $\mathrm{Zn}^{2+}$, each $\mathrm{Zn}^{2+}$ can adsorb three oxygen-containing intermediates one by one, as shown in Figure 2. Total energies for the interaction of $\mathrm{RO}^{*}$ and $\mathrm{ROO}^{*}$ on $\mathrm{Zn}^{2+}$ are shown in Table S1. The corresponding bonding energies for each coordination 
process of $\mathrm{RO}^{*}$ and $\mathrm{ROO}^{*}$ are shown in Figure 3. It is worth noting that a $\mathrm{Zn}^{2+}$ interacts with the first $\mathrm{RO}^{*}$ and the energy of the system is $-7.15 \mathrm{eV}$ negative than that of before. When the second $\mathrm{RO}^{*}$ is coordinated, the bonding energy is $-5.41 \mathrm{eV}$. The coordination energy of $\mathrm{Zn}^{2+}$ to the third $\mathrm{RO} *$ is $-1.73 \mathrm{eV}$. It is conventionally accepted that the energetic of chemisorption is more negative than $-0.5 \mathrm{eV} .{ }^{[36]}$ For -1.73 $\mathrm{eV}$ is much more negative than $-0.5 \mathrm{eV}$, it is reasonable that $\mathrm{Zn}^{2+}$ might coordinates the fourth $\mathrm{RO} *$. This strongly suggests that the more $\mathrm{RO}^{*}$ is interacted with $\mathrm{Zn}^{2+}$, the more positive the system energy is. On the other hand, a $\mathrm{Zn}^{2+}$ coordinates with three $\mathrm{ROO}^{*}$ one by one, with the energy of $-6.39 \mathrm{eV},-3.12 \mathrm{eV}$ and -1.53 $\mathrm{eV}$ respectively. Obviously, $\mathrm{Zn}^{2+}$ possess a great interaction effect on $\mathrm{RO}^{*}$ and $\mathrm{ROO}^{*}$. Considering these radicals (RO* and $\mathrm{ROO}^{*}$ ) with high activity and short lifetime, a $\mathrm{Zn}^{2+}$ nearly cannot coordinate with 2 or 3 radical intermediates. Reasonably, the first coordination of $\mathrm{Zn}^{2+}$ with $\mathrm{RO}^{*}$ or $\mathrm{ROO}^{*}$ is closer to the actual experiment. The first coordination energy is much more negative, which will affect them to abstract $\mathrm{H}$ atom from cumene. Therefore, the coordination effect of $\mathrm{Zn}^{2+}$ affects the reaction (3) and (5). The experimental result shows that there is no oxidation product, so it could be inferred that $\mathrm{Zn}^{2+}$ directly inhibited the steps involved in cumene. Moreover, $\mathrm{RO}^{*}$ and $\mathrm{ROO}^{*}$ are both produced by $\mathrm{R}^{*}$, the effect of $\mathrm{Zn}^{2+}$ on extraction of $\mathrm{H}$ atom from cumene should be also very vital.

a

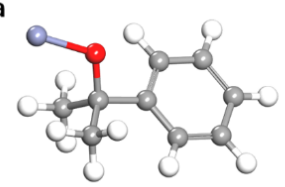

d

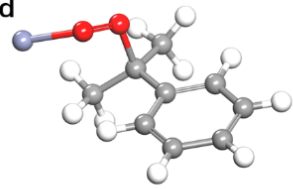

b

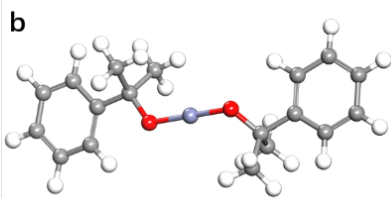

e

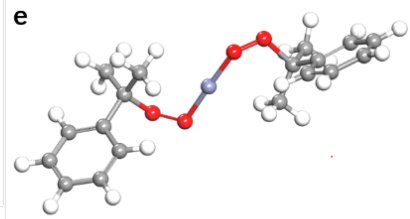

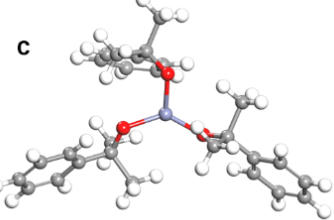

f

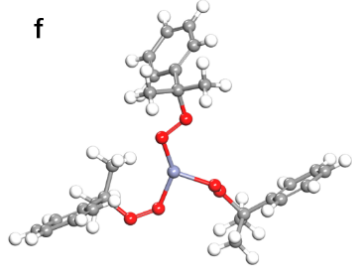

Figure 2Structural optimization for the interaciton of oxygen-containing intermediates (RO., ROO.) on $\mathrm{Zn}^{2+}$. (a) $\mathrm{Zn}(\mathrm{RO} \cdot)^{2+}$, (b) $\mathrm{Zn}(\mathrm{RO} \cdot)_{2}{ }^{2+}$, (c) $\mathrm{Zn}(\mathrm{RO} \cdot)_{3}{ }^{2+}$, (d) $\mathrm{Zn}(\mathrm{ROO} \cdot)^{2+}$, (e) $\mathrm{Zn}(\mathrm{ROO} \cdot)_{2}{ }^{2+}$ and (f) $\mathrm{Zn}(\mathrm{ROO} \cdot)_{3}{ }^{2+}$. 


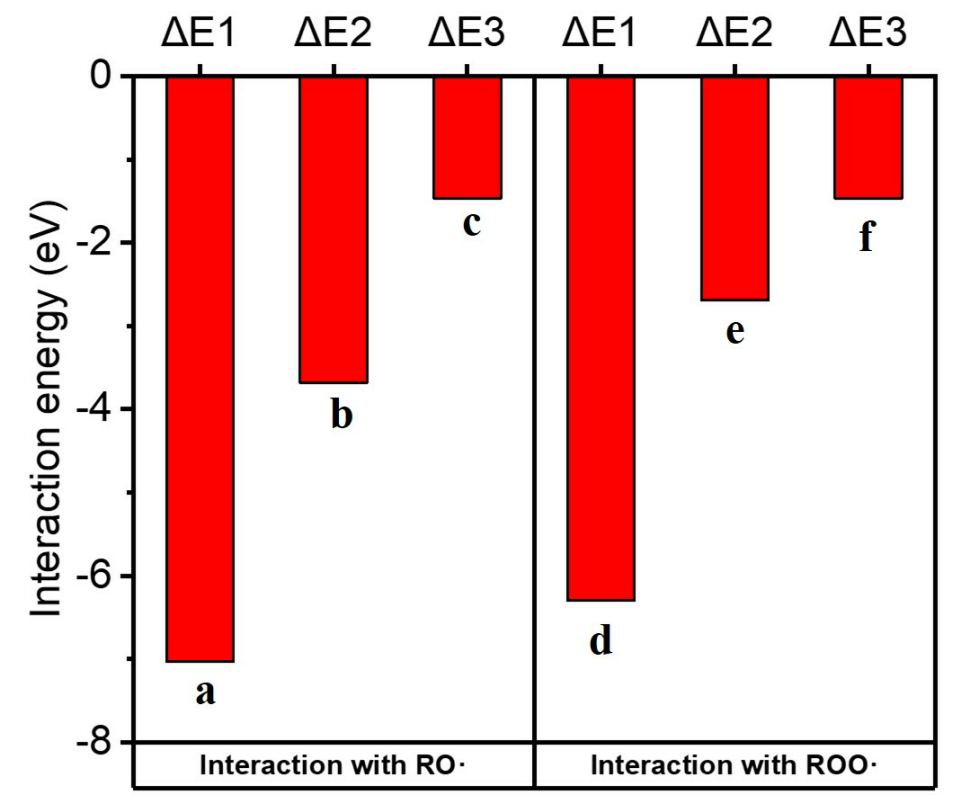

Figure 3 The bonding energy for each coordination process. (a)-(f) correspond to the coordination states in Figure 2.

When $\mathrm{Zn}^{2+}$ is involved in the reaction (1), the coordination effect needs to be considered. As previous research has shown, the $\mathrm{Zn}^{2+}$ ions could coordinate with oxygen species to form different complexes. ${ }^{[37,38]}$ So, $\mathrm{Zn}^{2+}$ with different hydration number $(0,2,4,6)$ was designed in the calculation. While a $\mathrm{Zn}^{2+}$ in the solution, there are 4 models (including $\left[\mathrm{Zn}\left(\mathrm{H}_{2} \mathrm{O}\right)_{\mathrm{x}}\right]^{2+}$, for $\left.\mathrm{x}=0,2,4,6\right)$. Optimized models showed that no matter what hydration number is, both $\mathrm{Zn}^{2+}$ ion can coordinate with ROS activated by CNTs, as shown in Figure 4. The bond length of $\mathrm{Zn}^{2+}-\mathrm{O}$ (oxygen species) is calculated and shown in Figure S1. When the hydration number was $0,2,4,6$, the bond length of $\mathrm{Zn}^{2+}$-ROS is $1.84 \AA, 1.80 \AA, 1.87 \AA$ and 1.95 $\AA$ respectively. All of zinc compounds could form bonds with ROS diffused into solution. As the hydration number goes up, the bond length between $\mathrm{Zn}^{2+}$ and ROS increases. It is indicated that a $\mathrm{Zn}^{2+}$ coordinated sufficient oxygen-containing groups would weakly adsorb ROS. Similarly, it also would weakly adsorb RO. and ROO. (Table S2). In other words, if each $\mathrm{Zn}^{2+}$ coordinates sufficient oxygen-containing groups, the inhibition is weakened or even eliminated.

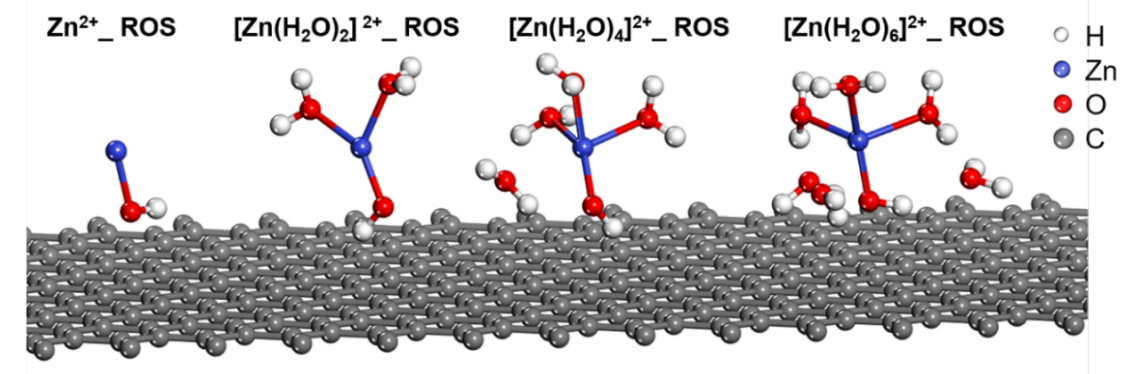

Figure 4 Optimization of different zinc compounds and ROS diffused from the surface of the CNTs. $(\mathrm{OH}$ simply represents ROS). 
To prove this view, an experiment has been designed to add zinc acetate $\left(\mathrm{Zn}\left(\mathrm{CH}_{3} \mathrm{COO}\right)_{2}\right)$ into the cumene oxidation reaction catalyzed by CNTs. The result shows that the conversion of cumene with CNTs and $\mathrm{Zn}\left(\mathrm{CH}_{3} \mathrm{COO}\right)_{2}$ was $37.6 \%$, which was $4 \%$ lower than that of only with CNTs. But, compared with zinc halide, the inhibition effect of zinc acetate is very weak because $\mathrm{Zn}^{2+}$ is already saturated with oxygencontaining $\mathrm{CH}_{3} \mathrm{COO}^{-}$groups. This further elucidates the relationship between the coordination of $\mathrm{Zn}^{2+}$ with oxygen-containing groups and the inhibition of $\mathrm{Zn}^{2+}$ on cumene oxidation. $\mathrm{Zn}^{2+}$ combines with $\mathrm{ROS}$ in the system, making it hard to extract $\mathrm{H}$ atom from cumene.

The reaction (1) is the dissociation of hydrogen radical $(\mathrm{H} \cdot)$ and the production of $\mathrm{R}$. The production of $\mathrm{R}$. is directly related to the generation of RO and ROO. However, the bonding energy of $\mathrm{H}$ - with tertiary carbon is about $3.8 \mathrm{eV}$ (Table S3). Besides that, even if the initial reaction of cumene successfully occurs. The radicals generated from the initial reaction will quickly combine to cumene because of its instability. This is the reason why it is difficult for cumene to oxidize without catalyst. The energy barrier of the initial reaction on different catalysts is shown in Figure 5 and Table S4. ROS diffused from the surface of the CNTs effectively reduce the initial reaction energy barrier to $0.55 \mathrm{eV}$, which can account for the conversion of cumene by CNTs. On this basis, after adding $\mathrm{Cu}^{2+}$, the energy barrier is lower as $0.18 \mathrm{eV}$ which can explain the promotion of $\mathrm{Cu}^{2+}{ }^{214]}$ The situation with adding $\mathrm{Zn}^{2+}$ is completely the opposite, the energy barrier goes up to $1.90 \mathrm{eV}$ with adding $\mathrm{Zn}^{2+}$. It is reasonable to deduce that the inhibition effect of $\mathrm{Zn}^{2+}$ ions on cumene oxidation is due to the strong interaction of $\mathrm{Zn}^{2+}$ between ROS in the system, which leads to the increase of the energy barrier of the initial reaction.

Figure 5 Potential energy surface of the initial reaction of cumene with different metal ion.

According to the above theoretical calculations, $\mathrm{Zn}^{2+}$ can strongly coordinate $\mathrm{ROS}$ due to its positive charge and sufficient space. According to the bonding energy between $\mathrm{Zn}^{2+}$ and ROS, it is difficult to break out ROS and $\mathrm{Zn}^{2+}$. ROS is the key substance for the oxidation of cumene catalyzed by carbon nanotubes, so the initial reaction of cumene cannot be carried out. Moreover, it is more difficult to extract $\mathrm{H}$ atom from cumene to generate oxygen-containing free radicals (RO. and ROO.). This indicates that the interaction characteristic between the catalyst and reactive oxygen should be considered for the rational design of catalysts. In addition to $\mathrm{Zn}^{2+}$, the role of other metal ions in the cumene oxidation may also be worth considering, including the coordination ability to ROS and the inducted chain growth process.

\section{Conclusions}

In this work, the inhibition effect of $\mathrm{Zn}^{2+}$ on the catalytic oxidation of cumene was found by experiments, and the reason was studied by DFT. There are two inhibitory effects of $\mathrm{Zn}^{2+}$ on cumene oxidation. Firstly, $\mathrm{Zn}^{2+}$ is able to strongly coordinate ROS activated by CNTs, inhibiting this critical chain-initiation process of cumene oxidation. After adding $\mathrm{Zn}^{2+}$, the energy barrier of initial reaction increases to $1.90 \mathrm{eV}$, which is nearly 4 times higher than that of the ROS promoted-process. Secondly, the interaction of radicals (RO-, ROO.) and $\mathrm{Zn}^{2+}$ leads to those radicals out of chain propagation reaction and annihilate. This work provides a better understanding of carbon catalyzed cumene radical reactions. At the same time, it is noteworthy that the influence of metal ion impurity on the oxidation activity of cumene in industrial application.

Conflicts of interest

There are no conflicts to declare.

\section{Acknowledgements}

We would like to acknowledge the financial support from the National Natural Science Foundation of China (No. 21872041).

\section{References}

1. G. B. Shul'pin, D. V. Muratov, L. S. Shul'pina, A. R. Kudinov, T. V. Strelkova, P. V. Petrovskiy, Appl Organomet Chem, 2008, 22, 684-688. 
2. H. Yu, F. Peng, J. Tan, X. Hu, H. Wang, J. Yang, W. Zheng, Angew Chem Int Ed , 2011 , 50, 3978-3982.

3. L. Luo, H. Liu, G. Y. Li, C. W. Hu, RSC Adv, 2016 , 6, 55463-55471.

4. K. E. Kharlampidi, K. A. Tereshchenko, T. S. Nurmurodov, D. A. Shiyan, N. P. Miroshkin, N. N. Ziyatdinov, A. S. Ziganshina, N. M. Nurullina, S. L. Khursan, N. V. Ulitin, Chem Eng J,2020, 392.

5. I. Di Somma, R. Andreozzi, M. Canterino, V. Caprio, R. Sanchirico,AIChE , 2008 , 54, 1579-1584.

6. V. M. Zakoshansky, Petrol Chem, 2007 , 47, 307-307.

7. D. G. Huang, M. H. Han, J. F. Wang, Y. Jin, Chem Eng J,2002 , 88, 215-223.

8. A. Nowacka, R. Vismara, G. Mercuri, M. Moroni, M. Palomino, K. V. Domasevitch, C. Di Nicola, C. Pettinari, G. Giambastiani, I. X. F. X. Llabres, S. Galli, A. Rossin, Inorg Chem, 2020 , 59, 8161-8172.

9. M. Yang, G. Qu, C. P. Huang, X. M. Hang, Y. X. Li, B. H. Chen,Ind Eng Chem Res, 2019 , 58, 1978519793.

10. D. S. Su, G. Wen, S. Wu, F. Peng, R. Schlogl, Angew Chem Int Ed, 2017 , 56, 936-964.

11. S. X. Liao, F. Peng, H. Yu, H. J. Wang, Appl Catal A-Gen,2014, 478, 1-8.

12. D. S. Su, J. Zhang, B. Frank, A. Thomas, X. Wang, J. Paraknowitsch, R. Schlogl, ChemSusChem, 2010 , 3, 169-180.

13. Y. M. Chi, M. L. Zhu, Y. H. Li, H. Yu, H. J. Wang, F. Peng, Catal Sci Technol, 2016 , 6, 2396-2402.

14. J. Deng, Y. H. Li, Y. H. Cao, H. J. Wang, H. Yu, Q. Zhang, J. L. Zuo, F. Peng, Catal Sci Technol, 2020 , 10, 2523-2530.

15. S. X. Liao, Y. M. Chi, H. Yu, H. J. Wang, F. Peng,ChemCatChem, 2014, 6, 555-560.

16. Y. Li, Z. Qiao, Y. Cao, H. Wang, H. Liang, H. Yu, F. Peng, ChemSusChem, 2019 , 12, 1133-1138.

17. R. Khorrampour, M. D. Esrafili, N. L. Hadipour, Physica E Low Dimens Syst Nanostruct , 2009 , 41, 1373-1378.

18. C. L. Mu, Y. H. Cao, H. J. Wang, H. Yu, F. Peng, Chem Eng Sci, 2018 , 177, 391-398.

19. C. L. Mu, K. T. Huang, T. Y. Cheng, H. J. Wang, H. Yu, F. Peng, Chem Eng J, 2016 , 306, 806-815.

20. P. Makowski, R. Demir Cakan, M. Antonietti, F. Goettmann, M. M. Titirici, ChemComm, 2008 , 9991001.

21. B. Delley, J Chem Phys, 2000 , 113, 7756-7764.

22. J. P. Perdew, K. Burke, M. Ernzerhof, Phys Rev Lett,1996 , 77, 3865 - 3868.

23. S. Grimme, J. Antony, S. Ehrlich, H. Krieg, J Chem Phys,2010 , 132, 154104.

24. A. Klamt, G. Schüürmann, J Chem Soc Perkin Trans, 2.1993, 799 - 805.

25. E. Zeynalov, N. S. Allen, N. Salmanova, V. Vishnyakov, J Phys Chem Solids, 2019 , 127, 245-251.

26. J. Luo, F. Peng, H. Yu, H. J. Wang, W. X. Zheng, ChemCatChem,2013 , 5, 1578-1586.

27. A. Nowacka, P. Briantais, C. Prestipino, F. X. L. I. Xamena, ACS Sustain Chem Eng, 2019 , 7, 7708-7715.

28. R. Selvin, G. R. Rajarajeswari, L. S. Roselin, V. Sadasivam, B. Sivasankar, K. Rengaraj, Appl Catal A-Gen, 2001 , 219, 125-129.

29. N. Turovskij, E. Raksha, Y. Berestneva, A. Eresko, J Organomet Chem, 2020 , 922, 121371.

30. U. Neuenschwander, I. Hermans, J Catal, 2012, 287, 1-4. 
31. L. Valgimigli, A. Baschieri, R. Amorati, J Mater Chem B,2018 , 6, 2036-2051.

32. I. Hermans, P. A. Jacobs, J. Peeters, J Mol Catal A-Chem,2006 , 251, 221-228.

33. U. Neuenschwander, I. Hermans, Phys Chem Chem Phys,2010 , 12, 10542-10549.

34. L. I. Matienko, L. A. Mosolova, G. E. Zaikov, Russ Chem Rev,2009 , 78, 211-230.

35. I. Hermans, P. A. Jacobs, J. Peeters, Chemistry,2006 , 12, 4229-4240.

36. M. M. Montemore, M. A. van Spronsen, R. J. Madix, C. M. Friend,Chem Rev, 2018 , 118, 2816-2862.

37. T. Deng, X. Cui, Y. Qi, Y. Wang, X. Hou, Y. Zhu, Chem Commun,2012 , 48, 5494-5496.

38. Q. Xu, L. F. Chen, J Appl Polym Sci, 1999 , 71, 1441-1446. 